\title{
Efficacy of vinorelbine-based neoadjuvant chemotherapy in breast cancer: A systematic review and meta-analysis of randomized controlled trials
}

\author{
HUI GAO ${ }^{1}$, QIUYUN LI ${ }^{2}$, WEI WEI ${ }^{2}$, YI JIANG ${ }^{2}$, HUAWEI YANG ${ }^{2}$ and JIANLUN LIU ${ }^{2}$ \\ ${ }^{1}$ Department of Breast Surgery, Ruikang Hospital Affiliated to Guangxi University of Chinese Medicine, \\ Nanning, Guangxi 530001; ${ }^{2}$ Department of Breast Surgery, The Affiliated Cancer Hospital \\ of Guangxi Medical University, Nanning, Guangxi 530021, P.R. China
}

Received February 4, 2015; Accepted March 31, 2015

DOI: $10.3892 / \mathrm{mco} .2015 .576$

\begin{abstract}
The present study aimed to compare the effects of vinorelbine-based neoadjuvant chemotherapy and vinorelbine-free regimens. A meta-analysis of all the relevant randomized controlled trials was performed to investigate the improvement in pathological complete response (pCR), overall response rate (ORR) and breast-conserving surgery (BCS). The PubMed and Embase databases were searched for relevant studies reporting randomized controlled trials comparing vinorelbine-based neoadjuvant chemotherapy with vinorelbine-free regimens until July 2013. Risk ratios/odds ratio and 95\% confidence intervals (CIs) were used to estimate the association between vinorelbine in neoadjuvant chemotherapy and various efficacy outcomes. Fixed- or random-effect models were adopted to pool the data. Five eligible studies with a total of 1,495 patients were included in the meta-analysis. Compared to vinorelbine-free chemotherapy, vinorelbine-based regimens demonstrated no significant improvement in clinical outcomes including: pCR [relative risk (RR) $=1.016$; 95\% CI, 0.738-1.399; $\mathrm{P}=0.922]$, ORR ( $\mathrm{RR}=1.048 ; 95 \% \mathrm{CI}, 0.969-1.133 ; \mathrm{P}=0.239)$ and BCS (RR=1.764; 95\% CI, 0.734-4.239; $\mathrm{P}=0.205)$. However, vinorelbine-based regimens were associated with a lower incidence of grade 3-4 alopecia (OR, 0.617 ; 95\% CI, 0.448-0.848; $\mathrm{P}=0.003$ ). In a hierarchical analysis for patients who received neoadjuvant chemotherapy, the proportion of subjects achieving pCR was significantly increased when HER2-amplified ( $\mathrm{RR}=2.31$; 95\% CI, 1.20-4.43; $\mathrm{P}=0.01)$ and hormone receptor negative ( $R R=0.488 ; 95 \% \mathrm{CI}, 0.263-0.908 ; \mathrm{P}=0.023)$. The present review confirms that neoadjuvant chemotherapy
\end{abstract}

Correspondence to: Professor Jianlun Liu, Department of Breast Surgery, The Affiliated Cancer Hospital of Guangxi Medical University, 71 Hedi Road, Nanning, Guangxi 530021, P.R. China E-mail: 250887556@qq.com

Key words: breast cancer, neoadjuvant chemotherapy, vinorelbine, meta-analysis vinorelbine-based regimens are unlikely to emerge as superior to $\mathrm{pCR}, \mathrm{ORR}$ and BCS. Hierarchical analysis indicated that the HER2-amplified and hormone receptor-negative patients were significantly associated with a pathological response rate.

\section{Introduction}

Neoadjuvant chemotherapy has emerged as the standard of care in the treatment of inoperable and operable locally advanced breast cancer. Neoadjuvant chemotherapy was used to afford tumor shrinkage and render tumors treatable for inoperable and locally advanced disease $(1,2)$. Compared to patients with operable primary breast cancer, neoadjuvant chemotherapy can downstage the tumor so that breast-conserving surgery (BCS) becomes an alternative to mastectomy (2). Another benefit of neoadjuvant therapy is the unique opportunity for the evaluation of treatment response with pathological complete response ( $\mathrm{pCR}$ ) acting as a surrogate marker of survival. This allows a more rapid assessment of the efficacy of novel chemotherapeutic agents, also enabling early cessation of ineffective treatments and providing an opportunity to individualise patient treatment at an early stage. Despite the proven benefits of neoadjuvant treatment, no neoadjuvant chemotherapy regimens were recommended as the treatment of first choice. Anthracycline- or taxane-based neoadjuvant chemotherapy regimens are used widely, and other agents have been explored in clinical studies.

Vinorelbine is a semi-synthetic third generation vinca alkaloid with a broad spectrum of antitumor activity. Vinorelbine acts on the dynamic equilibrium of tubulin in the microtubulin apparatus of the cell. It inhibits tubulin polymerisation and binds preferentially to mitotic microtubules and blocks mitosis at $\mathrm{G}_{2}-\mathrm{M}$, causing cell death in interphase or at the following mitosis $(3,4)$. The Breast Cancer Guidelines Committee of the National Comprehensive Cancer Network $(\mathrm{NCCN})$ recommend vinorelbine as one of the first choices for patients with recurrent or metastatic breast cancer, but there are also other clinical studies exploring neoadjuvant treatment (5-8). Vinorelbine-based regimens were as effective and well-tolerated as vinorelbine-free regimens for breast cancer patients, and called for a neoadjuvant chemotherapy regimen 
as an option for primary breast cancer (5). To more clearly understand vinorelbine-based regimens in neoadjuvant treatment for breast cancer patients, a meta-analysis was performed of the randomized controlled trials comparing neoadjuvant therapies with and without the drug for patients with breast cancer.

\section{Materials and methods}

Publication search strategy. PubMed and Embase were searched until July 2013 for randomized controlled trials regarding vinorelbine-based neoadjuvant chemotherapy for breast cancer. No language restrictions were used. The following search terms were used: 'Vinorelbine', 'neoadjuvant', 'preoperative', 'breast neoplasm' and 'breast cancer'. Manual searches were performed by reviewing the reference lists of retrieved studies, textbooks and review studies to identify additional potentially eligible studies.

Inclusion criteria. To be considered eligible for inclusion in the meta-analysis, the study criteria had to include: i) Patient diagnosis of breast cancer without metastasis; ii) being a controlled trial; iii) using vinorelbine in the neoadjuvant setting to treat breast cancer; and iv) reporting relative risk (RR) with a $95 \%$ confidence interval (CI); if not, the reported data of pCR, overall response rate (ORR) or BCS outcomes were sufficient to calculate them.

Data extraction. Two investigators (Hui Gao and Qiuyun Li) independently extracted information from the included studies. Disagreement was resolved by discussion between the two investigators. When multiple studies covering the same trial were retrieved, or when studies had overlapping study publications, only the largest number of participants with the most recent publication was included. The following data were extracted: First author's family name, year of publication, country of origin, regimens, number of cases and doses of regimens. Study quality was assessed using the Jadad score. Two investigators independently evaluated all the included trials based on an appropriate randomization method (0-2), an appropriate blinding method (0-2) and the study withdrawals and dropouts (0-1). Trials were considered to be of low quality if they reported none of the items, medium quality if they reported on $<3$ and of high quality if they reported on 3-5.

Statistical methods. All the statistical tests were performed using Stata/SE12.0 software (version 12.0; Stata Corp., College Station, TX, USA). The strength of association between the vinorelbine-based and vinorelbine-free regimens was assessed by calculating RR with $95 \%$ CIs based on the numbers in the controls. To test for heterogeneity in the included studies and analyze the statistical heterogeneity using the $\chi^{2}$ test, $\mathrm{P} \leq 0.10$ was considered to indicate a statistically significant difference. When heterogeneity did not exist between the results, $\mathrm{I}^{2}$ heterogeneity quantitative analysis was used and the significance level was set at $50 \%$, so $\mathrm{I}^{2}>50 \%$ indicated heterogeneity in the results. A random-effects model was used to pool the analysis when there was a genuine difference in the result. By contrast, if the difference in the studies was due to chance, then a fixed-effects model was used for meta-analysis.

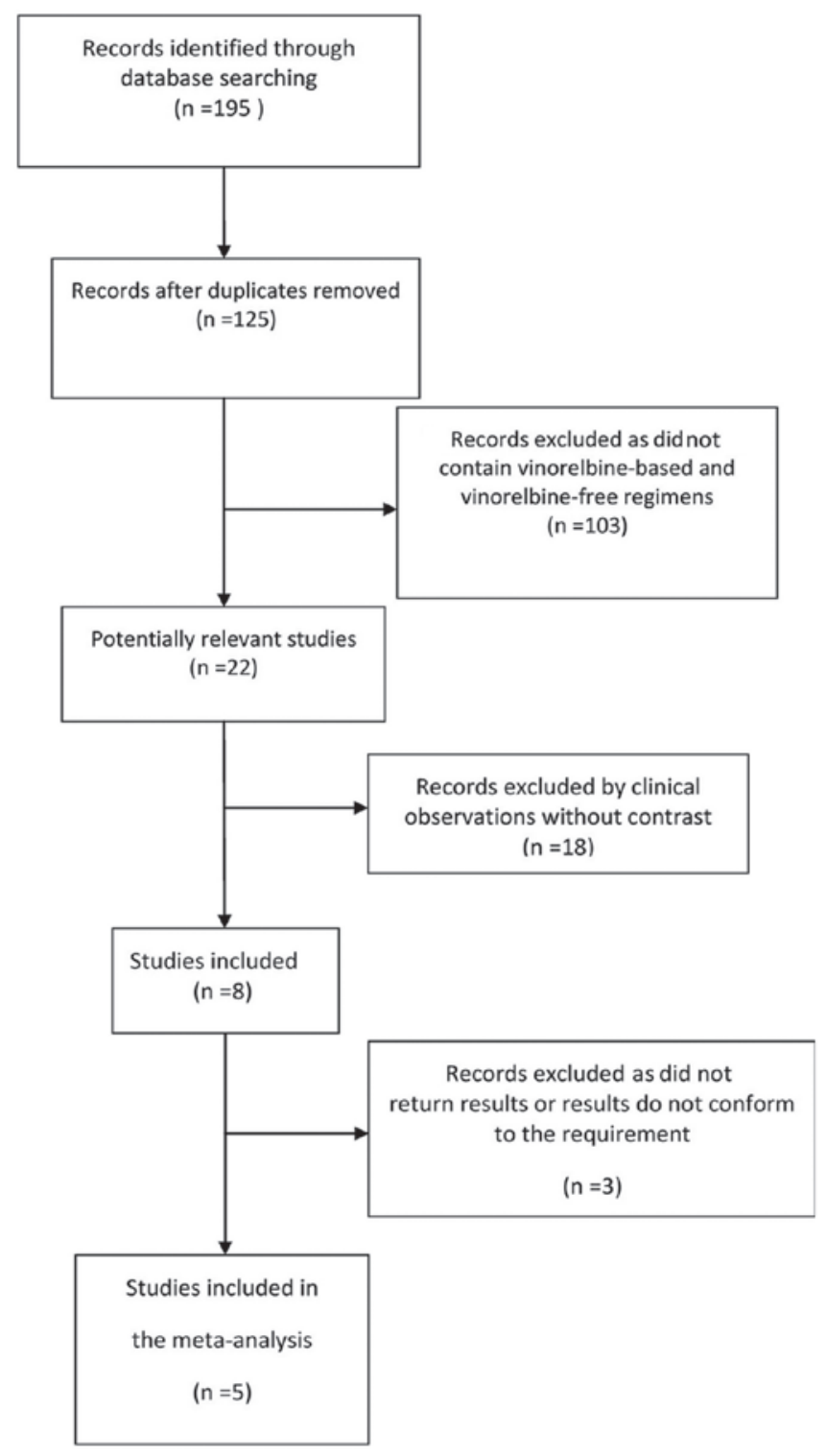

Figure 1. Flow chart of study selection.

\section{Results}

Patient characteristics. Five eligible studies (9-13) were identified with a total of 1,492 patients with early or operable breast cancer without distant metastasis according to the inclusion criteria (Fig. 1). In total, 675 patients were assigned to chemotherapy combined with vinorelbine and 817 to chemotherapy alone. The characteristics of the included trials are summarized in Table I. The median follow-up ranged between 2.2 and 5.1 years.

Krop et al (11) reported on a group receiving vinorelbine plus trastuzumab as neoadjuvant therapy and another receiving a standard combination of trastuzumab, docetaxel plus carboplatin. This study was only available as an abstract, while the full text was available for the remaining four studies. In the study by von Minckwitz et al (9), prior data for the group with complete or partial remission to 2 cycles TAC (docetaxel, doxorubicin and cyclophosphamide) followed by 4 or 6 cycles of TAC were excluded based on the inclusion criteria. All the studies included in the meta-analysis were 
Table I. Characteristics of studies.

\begin{tabular}{|c|c|c|c|c|c|c|}
\hline First author (year) & $\begin{array}{l}\text { No. of } \\
\text { patients }\end{array}$ & Agents and doses & Country & End-point & $\begin{array}{l}\text { Jadad } \\
\text { score }\end{array}$ & (Refs.) \\
\hline Krop (2010) & $\begin{array}{l}41 \\
39\end{array}$ & $\begin{array}{l}\text { N } 25 \mathrm{mg} / \mathrm{m}^{2} \mathrm{qwk}+\mathrm{H} 2 \mathrm{mg} / \mathrm{kg} \mathrm{qwk} \\
\text { T } 75 \mathrm{mg} / \mathrm{m}^{2} \mathrm{q} 3 \mathrm{wk}+\mathrm{C}^{1} \mathrm{AUC} 6 \mathrm{q} 3 \mathrm{wk}+\mathrm{H} 2 \mathrm{mg} / \mathrm{kg} \mathrm{qwk}\end{array}$ & America & pCR, ORR, BCS & 2 & (11) \\
\hline Minckwitz (2011) & $\begin{array}{l}321 \\
301\end{array}$ & $\begin{array}{l}\mathrm{T} 75 \mathrm{mg} / \mathrm{m}^{2}+\text { A } 50 \mathrm{mg} / \mathrm{m}^{2}+\mathrm{C} 500 \mathrm{mg} / \mathrm{m}^{2} \text { on day } 1 \\
\mathrm{~N} 25 \mathrm{mg} / \mathrm{m}^{2} \text { on days } 1 \text { and } 8+\mathrm{X} 1,000 \mathrm{mg} / \mathrm{m}^{2} \\
\text { twice a day on days } 1-14\end{array}$ & German & pCR, ORR, BCS & 3 & (9) \\
\hline Ferrero (1997) & $\begin{array}{l}68 \\
47 \\
77 \\
46\end{array}$ & $\begin{array}{l}\text { A } 40 \mathrm{mg} / \mathrm{m}^{2} \text { day } 1+\mathrm{V}^{1} 1.4 \mathrm{mg} / \mathrm{m}^{2} \text { day } 2+\mathrm{C} 300 \mathrm{mg} / \mathrm{m}^{2} \\
\text { days } 3-5+\mathrm{F} 500 \mathrm{mg} / \mathrm{m}^{2} \text { days } 3-5 \\
\text { A } 40 \mathrm{mg} / \mathrm{m}^{2} \text { day } 1+\mathrm{V}^{2} 3 \mathrm{mg} / \mathrm{m}^{2} \text { day } 2+\mathrm{C} 300 \mathrm{mg} / \mathrm{m}^{2} \\
\text { days } 3-5+\mathrm{F} 500 \mathrm{mg} / \mathrm{m}^{2} \text { days } 3-5 \\
\text { A } 30 \mathrm{mg} / \mathrm{m}^{2} \text { day } 1+\mathrm{V}^{3} 1.4 \mathrm{mg} / \mathrm{m}^{2} \text { day } 2+\mathrm{C} 100 \mathrm{mg} / \mathrm{m}^{2} \\
\text { days } 1-14+\mathrm{F} 500 \mathrm{mg} / \mathrm{m}^{2} \text { days } 1 \text { and } 8 \\
\text { A } 50 \mathrm{mg} / \mathrm{m}^{2} \text { day } 1+\mathrm{N} 25 \mathrm{mg} / \mathrm{m}^{2} \text { days } 1 \text { and } 8\end{array}$ & France & pCR, ORR, BCS & 2 & (13) \\
\hline Chua (2005) & $\begin{array}{l}238 \\
210\end{array}$ & $\begin{array}{l}\text { N } 25 \mathrm{mg} / \mathrm{m}^{2} \text { on days } 1 \text { and } 8+\mathrm{E} 60 \mathrm{mg} / \mathrm{m}^{2} \text { on day } 1 \\
\text { A } 60 \mathrm{mg} / \mathrm{m}^{2}+\mathrm{C} 600 \mathrm{mg} / \mathrm{m}^{2} \text { day } 1\end{array}$ & UK & pCR, ORR, BCS & 2 & (12) \\
\hline Gwak (2011) & $\begin{array}{l}53 \\
49\end{array}$ & $\begin{array}{l}\text { A } 50 \mathrm{mg} / \mathrm{m}^{2}+\text { D } 75 \mathrm{mg} / \mathrm{m}^{2} \\
\text { A } 50 \mathrm{mg} / \mathrm{m}^{2}+\mathrm{N} 25 \mathrm{mg} / \mathrm{m}^{2}\end{array}$ & Korea & pCR, ORR, BCS & 2 & (10) \\
\hline
\end{tabular}

$\mathrm{N}$, vinorelbine; H, herceptin; T, docetaxel; $\mathrm{C}^{1}$, carboplatin; A, doxorubicin; $\mathrm{C}$, cyclophosphamide; $\mathrm{X}$, capecitabine; $\mathrm{V}^{1}$, vincristine; $\mathrm{V}^{2}$, vindesine; $\mathrm{V}^{3}$, vinblastine; E, epirubicin; D, docetaxel; pCR, pathological complete response; ORR, overall response rate; BCS, breast-conserving surgery; qwk, every week; q3wk, every 3 weeks.

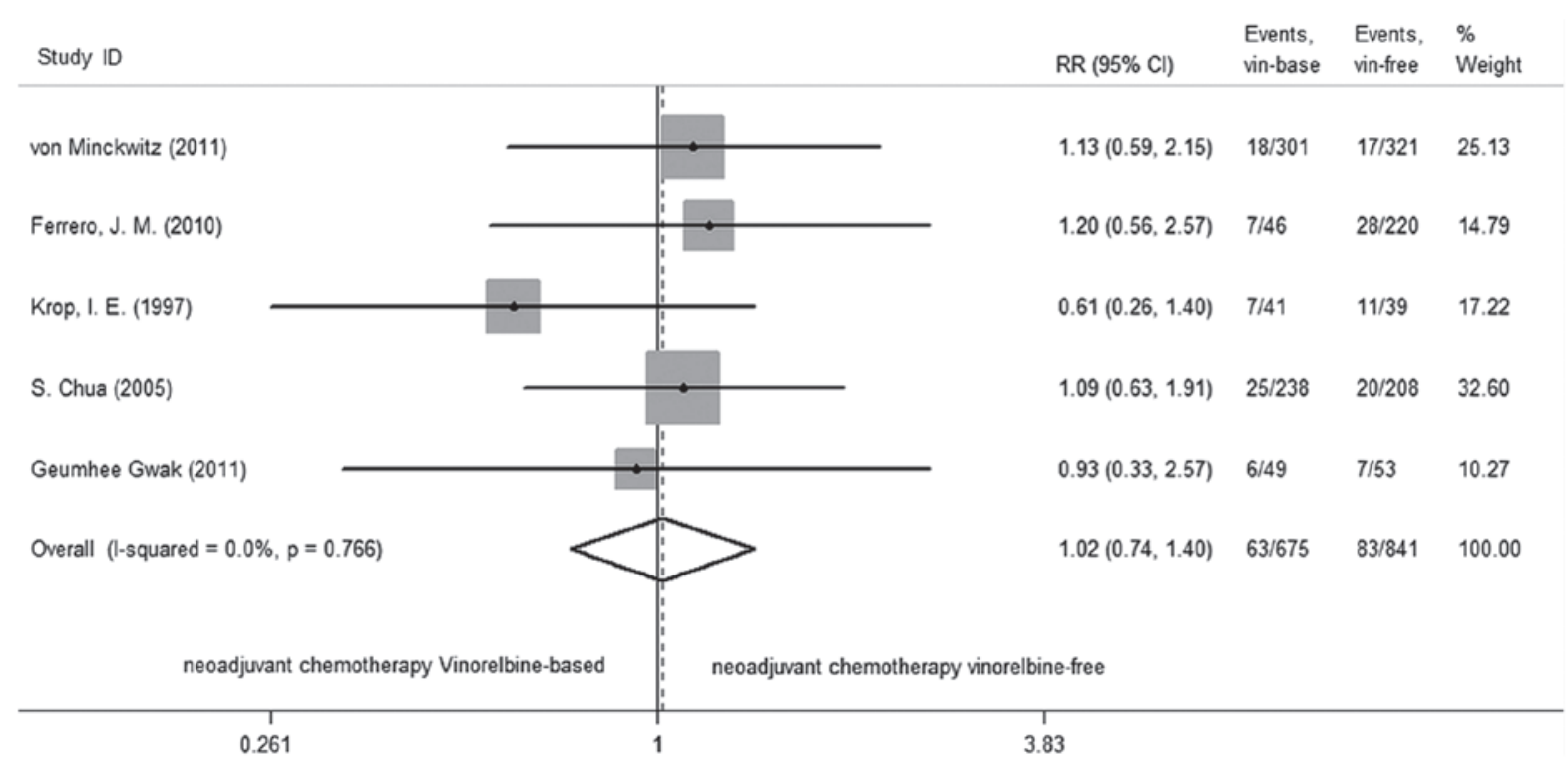

Figure 2. Fixed-effect model of the odds ratio (95\% CI) of pCR associated with vinorelbine (vin)-based regimens in relation to neoadjuvant chemotherapy. $\mathrm{pCR}$, pathological complete response; RR, relative risk; CI, confidence interval.

well-organized and had balanced populations. The main endpoint of all the five studies was pCR, and the second endpoint was ORR, BCS and various toxicities of the two arms.

First endpoint. Vinorelbine-based neoadjuvant chemotherapy was not associated with a significant improvement in $\mathrm{pCR}$ compared to vinorelbine-free regimens $(\mathrm{RR}=1.016$; 95\% CI, 0.738-1.399; $\mathrm{P}=0.922)$, There was no significant heterogeneity among studies $\left(\mathrm{P}=0.766, \mathrm{I}^{2}=0.0 \%\right.$; Fig. 2$)$.
Second endpoint. The next goal was the ORR in studies, following the generation of a fixed-effects model. There was no change in ORR $(\mathrm{RR}=1.048 ; 95 \% \mathrm{CI}, 0.969-1.133 ; \mathrm{P}=0.239)$ with vinorelbine-based regimens compared to vinorelbine-free regimens, and the test of heterogeneity did not exist in the studies $\left(\mathrm{P}=0.161, \mathrm{I}^{2}=39.1 \%\right.$; Fig. 3$)$.

There were three studies $(9,10,13)$ that reported breast-conserving surgery for 415 patients and showed that the difference in the BCS was not statistically significant $(\mathrm{RR}=1.764 ; 95 \% \mathrm{CI}, 0.734-4.239 ; \mathrm{P}=0.205)$ between 


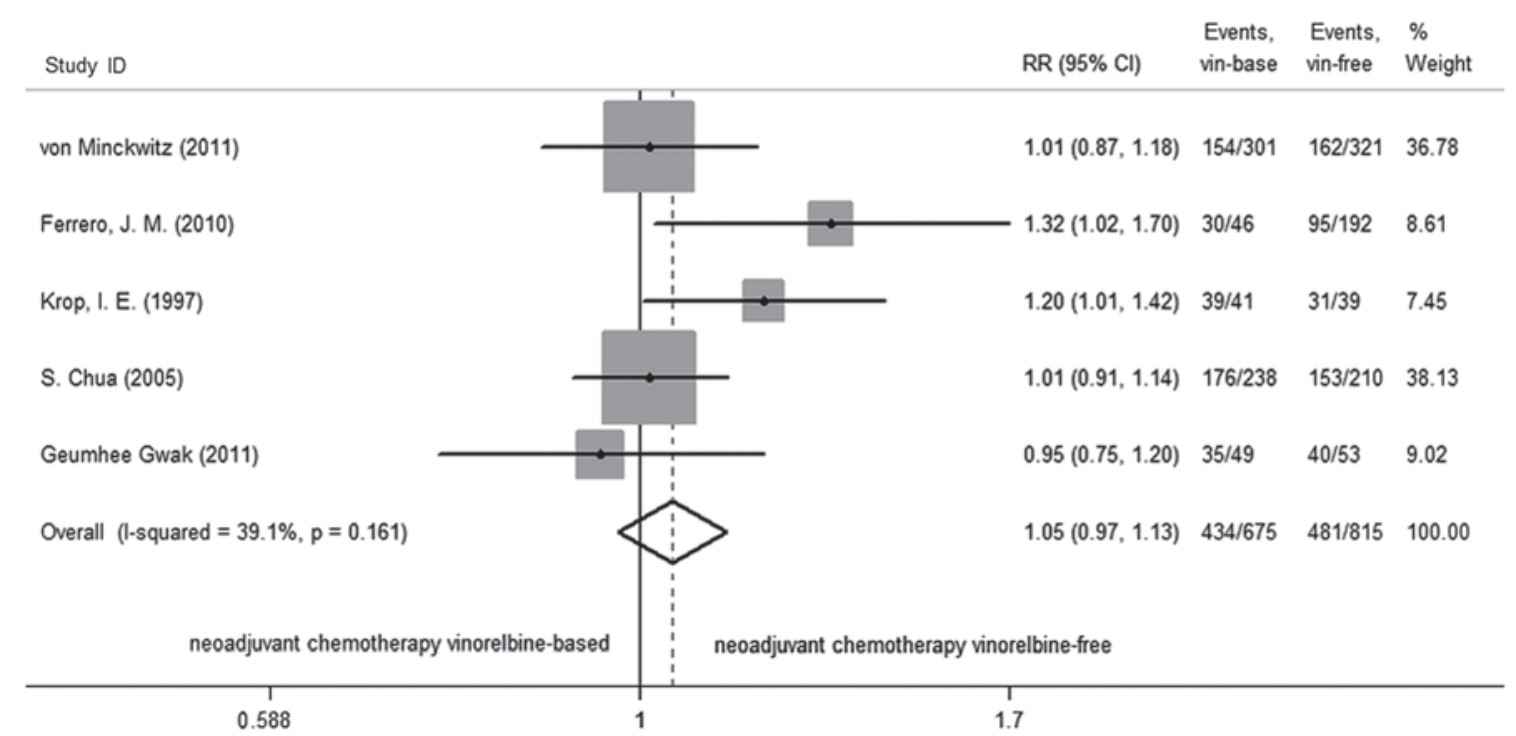

Figure 3. Fixed-effect model of the odds ratio (95\% CI) of ORR associated with vinorelbine (vin)-based regimens in association with neoadjuvant chemotherapy. ORR, overall response rate; $\mathrm{RR}$, relative risk; CI, confidence interval.

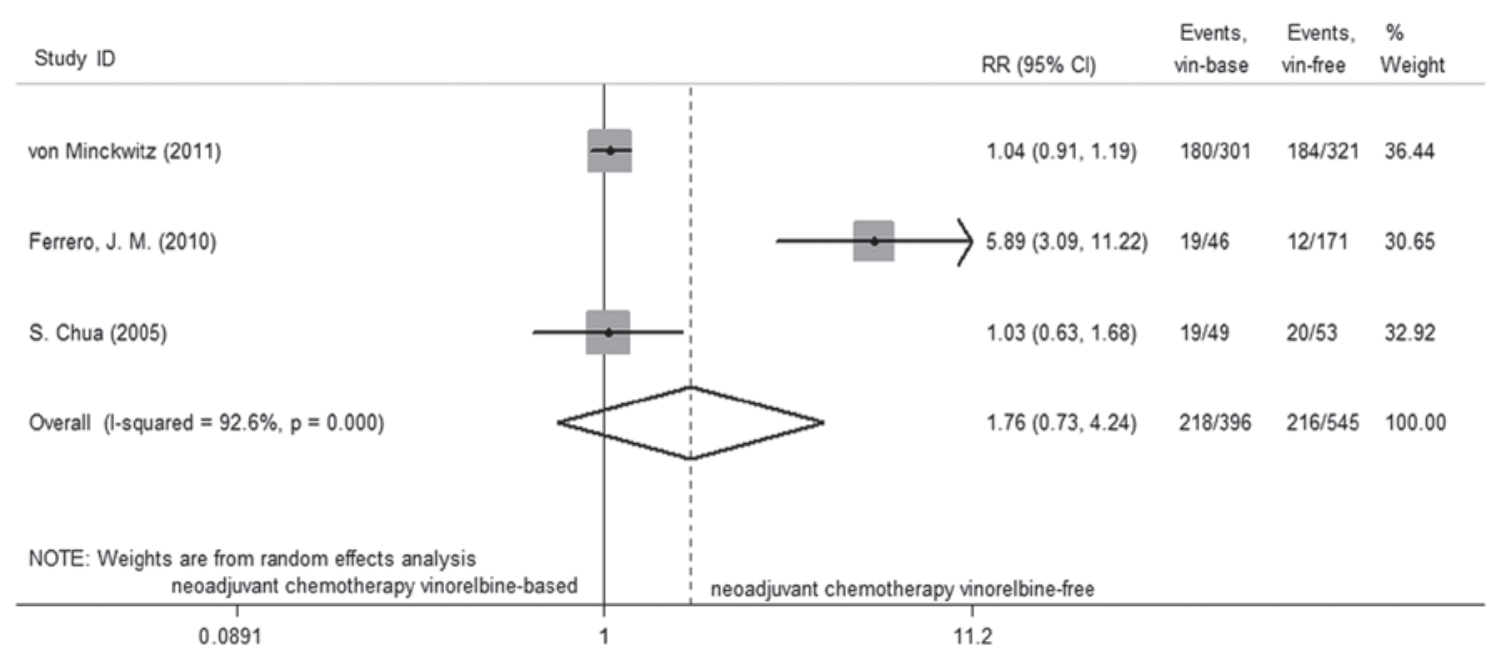

Figure 4. Random-effect model of the odds ratio (95\% CI) of BCS associated with vinorelbine (vin)-based regimens in association with neoadjuvant chemotherapy. BCS, breast-conserving surgery; RR, relative risk; CI, confidence interval.

vinorelbine-based and vinorelbine-free regimens with regards to neoadjuvant therapy. The test for heterogeneity was statistically significant $\left(\mathrm{P}=0.000, \mathrm{I}^{2}=92.6 \%\right)$. Therefore, an exploratory sensitivity analysis was performed to explore the source of the heterogeneity. Sensitivity analysis indicated that the outcome was not robust until the study by Ferrero et al (13) was excluded, and the heterogeneity could be mainly due to this study. The heterogeneity disappeared following the removal of this study, and the result also indicated that the difference in the BCS between the vinorelbine-based and vinorelbine-free regimens was not statistically significant $(R R=1.042$; 95\% CI, 0.917-1.148; $\mathrm{P}=0.526$ ), and the test of heterogeneity did not exist in studies ( $\mathrm{P}=0.953, \mathrm{I}^{2}=0.0 \%$; Fig. 4).

Two studies $(9,10)$ reported the postoperative outcomes in detail, as a hierarchical analysis, the rate of pCR of HER2 amplified was higher compared to HER2 non-amplified $(\mathrm{RR}=2.484 ;$ 95\% CI, 1.296-4.760; $\mathrm{P}=0.006$; Fig. 5) in neoadjuvant chemotherapy, and the test of heterogeneity did not exist $\left(\mathrm{P}=0.831, \mathrm{I}^{2}=0.0 \%\right)$. The hormone receptor status was associated with the rate of pCR in neoadjuvant chemotherapy. The rate of $\mathrm{pCR}$ of hormone receptor-negative was significant different compared to hormone receptor-positive $(\mathrm{RR}=0.488$; 95\% CI, 0.263-0.908, $\mathrm{P}=0.023$; Fig. 6), and the heterogeneity was not statistically significant $\left(\mathrm{P}=0.170, \mathrm{I}^{2}=46.9 \%\right)$.

Toxicity. Table II presents the summary estimates of the vinorelbine-based and vinorelbine-free neoadjuvant chemotherapy regimen toxicity. The results show that treatment with vinorelbine-based regimens is associated with a lower incidence of grade 3-4 (National Cancer Institute Common Teminology Criteria for Adverse Events grades 3-4) alopecia (OR, 0.617; 95\% CI, 0.448-0.848; $\mathrm{P}=0.003$ ). Heterogeneity among the studies in the analysis was not significant regarding alopecia $\left(\mathrm{P}=0.378, \mathrm{I}^{2}=0.0 \%\right)$. Neutropenia (OR, 0.436; 95\% CI, 0.185-1.145; $\mathrm{P}=0.058$ ), leukopenia (OR, 0.477; 95\% CI, 0.190-1.196; $\mathrm{P}=0.114)$ and mucositis $(\mathrm{OR}, 0.680$; 
Table II. Summary estimate of the toxicity of neoadjuvant chemotherapy regimens vinorelbine-based and vinorelbine-free.

\begin{tabular}{|c|c|c|c|c|c|c|c|c|}
\hline \multirow[b]{2}{*}{ Adverse events } & \multirow[b]{2}{*}{ No. of studies } & \multirow[b]{2}{*}{ No. of patients } & \multicolumn{2}{|c|}{ Heterogeneity } & \multirow[b]{2}{*}{ Statistical model } & \multicolumn{3}{|c|}{ Effect size } \\
\hline & & & P-value & $\mathrm{I}^{2}(\%)$ & & OR & $95 \% \mathrm{CI}$ & P-value \\
\hline Mucositis & 3 & 1,172 & 0.342 & 6.9 & Fixed-effect model & 0.680 & $0.390-1.185$ & 0.173 \\
\hline Alopecia & 2 & 1,070 & 0.378 & 0.0 & Fixed-effect model & 0.617 & $0.448-0.848$ & 0.003 \\
\hline Leukopenia & 2 & 1,070 & 0.001 & 90.5 & Random-effect model & 0.477 & $0.190-1.196$ & 0.114 \\
\hline Neutropenia & 3 & 1,172 & 0.000 & 92.0 & Random-effect model & 0.436 & $0.185-1.145$ & 0.058 \\
\hline
\end{tabular}

OR, odds ratio; $\mathrm{CI}$, confidence interval.

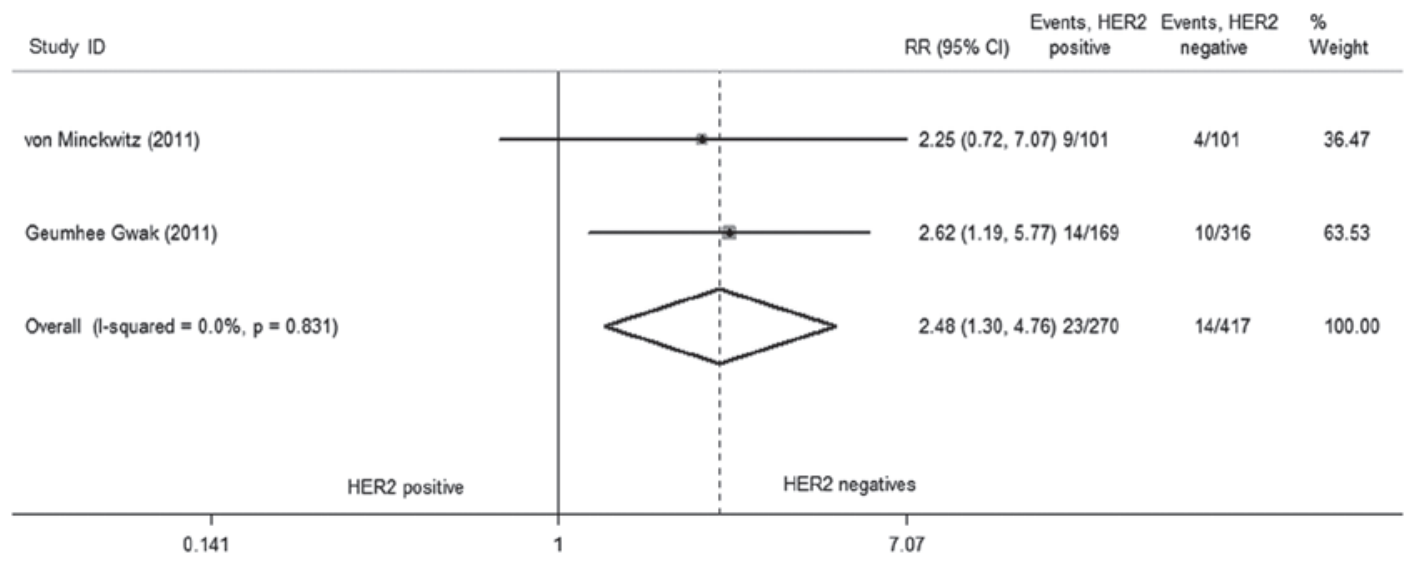

Figure 5. Fixed-effect model of the odds ratio (95\% CI) of HER2 status associated with pathological complete response. RR, relative risk; CI, confidence interval.

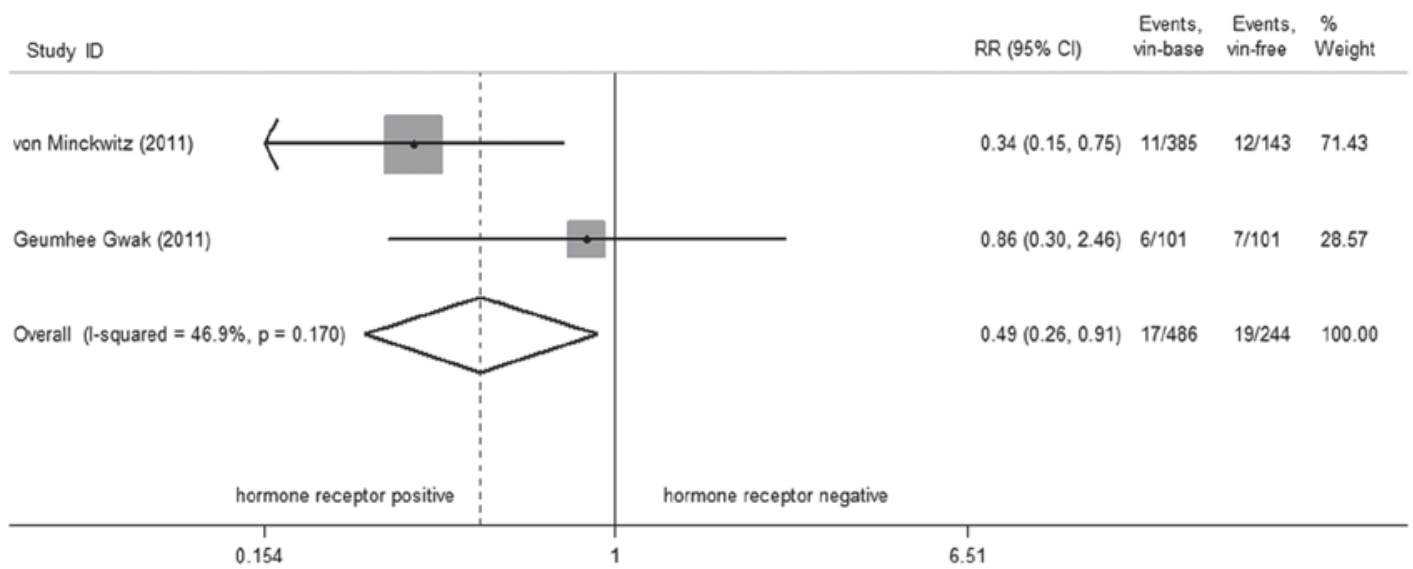

Figure 6. Fixed-effect model of the odds ratio $(95 \% \mathrm{CI})$ of hormone receptor status associated with pathological complete response. RR, relative risk; CI, confidence interval.

95\% CI, 0.390-1.185; $\mathrm{P}=0.173$ ) showed no statistical significance between the two arms. Heterogeneity among the studies in these analyses was significant, possibly due to the use of various agents at different dosages and the use of different control arms.

\section{Discussion}

Neoadjuvant chemotherapy is one of the common therapies for antitumor treatment, and the most common agents used in patients with breast cancer were anthracyclines and taxane, although uncertainty remains for which to recommend as first choice. Vinorelbine was recommended for the treatment of recurrent breast cancer by the NCCN guidelines, and the exploration in neoadjuvant therapy has been in progress. Several trials reported that vinorelbine combined with others agents caused a certain effect (7,14-16). In order to reassess the data that are already present in the literature with the largest possible statistical power, we carried out what is, to the best of our knowledge, the first meta-analysis of the effects of including vinorelbine as part of neoadjuvant polychemotherapy in patients with breast cancer. The findings show no benefit 
from neoadjuvant therapy in patients with vinorelbine-based compared to patients with vinorelbine-free regimens.pCR is the most powerful predictor of neoadjuvant chemotherapy $(17,18)$. Patients who achieved a pCR following neoadjuvant chemotherapy have an improved prognosis compared to those who remain with residual disease, which shows improvements in DFS and OS (19,20). A higher pCR rate has become one of the indicators of neoadjuvant chemotherapy. Therefore, the first goal of the present meta-analysis was pCR assessment. From the five studies, we identified vinorelbine-based regimens without any advantage in pCR (21). However, this shows another problem, as comparing to the vinorelbine-free regimens, vinorelbine-based regimens show no weakness in pCR in comparison to other regimens in neoadjuvant chemotherapy.

Although the present meta-analysis did not demonstrate an advantage of adding vinorelbine to neoadjuvant therapy for breast cancer, certain notable results did emerge from the included studies. von Minckwitz et al (9) and Gwak et al (10) reported four molecular outcomes in detail following surgery. Patients with HER2-amplified or hormone receptor-negative may have an additional benefit from neoadjuvant therapy to achieve pCR, which suggests that patients with different HER2 or hormone receptor status have different sensitivity for neoadjuvant therapy, although there were poor prognostic factors (22). The similar association between molecularly and pCR has been reported previously. Yoo et al (23) reported that the triple-negative is more likely to obtain pCR when neoadjuvant chemotherapy is administered, but there are worse survival outcomes. Houssami et al (24) also obtained similar results; triple-negative or $\mathrm{HER} 2^{+} / \mathrm{HR}^{-}$subtypes achieve higher odds of $\mathrm{pCR}$.

However, the present meta-analysis showed that the rate of BCS was not improved following neoadjuvant therapy. Certain strong heterogeneity was identified among the studies, and the reasons are list as followed. First, the decision of the surgeon to perform surgery was not only according to the result of neoadjuvant chemotherapy, but also considering other comprehensive situations. Second, the choice of surgery is strongly influenced by the willingness of the patient, the level of development of the country or region cognitive to breast cancer. Studies of different countries illustrate different BCS. Suen et al (25) reported that $21.9 \%$ of patients with early-stage breast cancer underwent BCS among 680 patients between January 2001 and December 2005 in Hong Kong. Clavarezza et al (26) reported that $34 \%$ of patients achieved breast-conserving surgery after four 3-weekly cycles of fluorouracil, epirubicin and cyclophosphamide followed by 12 cycles of weekly paclitaxel as neoadjuvant therapy in Italy. Further research and feasibility studies are required to demonstrate this.

The present analysis included five randomized controlled trials of varying quality and had the following limitations. First, despite the fact that no language restrictions were applied to the literature search, only one non-English language study was identified. It is possible that certain relevant clinical data published in other languages may have been overlooked. Second, one randomized controlled trial had no full text and another one had data pooled by the author, therefore, the heterogeneity is likely to increase. Finally, the characteristics of the included trials were varied in patients, time and dosage. The five trials did not use the double-blinding method. Future studies should attempt to minimize these possible sources of heterogeneity.

Despite the limitations of the present study, the results strongly demonstrate that vinorelbine-based neoadjuvant chemotherapy did not significantly improve pCR, ORR and BCS. HER2-amplified and hormone receptor-negative patients were significantly associated with the pathological response rate, but not the lymph node status and tumor size.

\section{References}

1. Cleator S, Parton M and Dowsett M: The biology of neoadjuvant chemotherapy for breast cancer. Endocr Relat Cancer 9: 183-195, 2002.

2. Charfare H, Limongelli S and Purushotham AD: Neoadjuvant chemotherapy in breast cancer. Br J Surg 92: 14-23, 2005.

3. Cros S, Wright M, Morimoto M, Lataste H, Couzinier JP and Krikorian A: Experimental antitumor activity of Navelbine. Semin Oncol 16 (Suppl 4): 15-20, 1989.

4. Goa KL and Faulds D: Vinorelbine. A review of its pharmacological properties and clinical use in cancer chemotherapy. Drugs Aging 5: 200-234, 1994.

5. Wang J, Xu L, Ye JM, Zhao JX, Duan XN and Liu YH: Effects of vinorelbine plus cisplatin as second-line neoadjuvant chemotherapy regimen in the treatment of breast cancer. Zhonghua Yi Xue Za Zhi 93: 93-95, 2013 (In Chinese).

6. Rivera-Rodriguez N, Cabanillas F, Lawrenson L, Negron V Pavia OA, Bruno M, Echenique MM, Carlo V, Liboy I, et al: Results of a novel neoadjuvant chemotherapy (NAC) regimen for breast cancer. J Clin Oncol (abstract) 31: e11610, 2013.

7. Carillio G, Aiello RA, Chiarenza M, Alì M, Mazzola A, Marco R, Taibi E, Fallica G, Casella T, Zacchia A, et al: Neoadjuvant trastuzumab and sequential chemotherapy with cisplatin, vinorelbine, and docetaxel for stage II-III breast cancer patients: Final results of a single institution phase II study. J Clin Oncol (abstract) 31: e11527, 2013.

8. Xu L, Ye JM, Zhao JX, Duan XN and Liu YH: Effects and toxicity of neoadjuvant chemotherapy with vinorelbine and cisplatin in treatment of operable breast cancer previously non-responsive to anthracyclines and taxanes-containing regimen: Analysis of 19 cases. Zhonghua Yi Xue Za Zhi 89: 683-685, 2009 (In Chinese).

9. von Minckwitz G, Blohmer JU, Costa S, Denkert C, Eidtmann H, Eiermann W, Gerber B, Hanusch C, Hilfrich J, Huober J, et al: Neoadjuvant chemotherapy adapted by interim response improves overall survival of primary breast cancer patients - Results of the GeparTrio trial. Cancer Res 71: S3-S2, 2011.

10. Gwak G, Kim JY, Park K, Shin YJ, Cho H, Park SJ, Yang GH, Bae BN, Kim KW and Han S: Comparison of doxorubicin plus docetaxel neoadjuvant chemotherapy with doxorubicin plus vinorelbine in primary breast cancer. J Breast Cancer 14: 129-134, 2011.

11. Krop IE, Flores L, Tuck DP, Ryan PD, Partridge AH, Morganstern D, Najita J, Lezon-Geyda K, Winer EP, Harris L: Phase II trial of preoperative vinorelbine/trastuzumab $(\mathrm{VH})$ or docetaxel/carboplatin/trastuzumab (TCH) in HER2-positive breast cancer with analysis of resistance mechanisms. J Clin Oncol 28: 15S, 2010.

12. Chua S, Smith IE, A'Hern RP, Coombes GA, Hickish TF, Robinson AC, Laing RW, O'Brien ME, Ebbs SR, Hong A, et al; TOPIC Trial Group: Neoadjuvant vinorelbine/epirubicin (VE) versus standard adriamycin/cyclophosphamide (AC) in operable breast cancer: Analysis of response and tolerability in a randomised phase III trial (TOPIC 2). Ann Oncol 16: 1435-1441, 2005.

13. Ferrero JM, Namer M, Dufour JF, Largillier R, Creisson A, Teissier E, Machiavello JC, Lallement M, Monticelli J and Abbes M: Neoadjuvant chemotherapy of locally advanced breast cancer: Historical comparison of 4 sequential combinations. Bull Cancer 84: 10-16, 1997.

14. Halim A and Wahba H: Second-line neoadjuvant vinorelbine and gemcitabine combination in locally advanced breast cancer showing no early response to TAC. Med Oncol 29: 454-458, 2012.

15. O'Regan RM, Gabram S, Styblo T, Rizzo M, Wood W, Srinivasiah J, Jonas W, Schnell F, Adams A, Nahta R, et al: Final results of a phase 2 trial using a novel, non-anthracycline neoadjuvant chemotherapy regimen in Her2-positive breast cancer. Cancer Res 72: 2703, 2012. 
16. Medioni J, Huchon C, Le Frere-Belda MA, Hofmann H, Bats AS, Eme D, Andrieu JM, Oudard S, Lecuru F and Levy E: Neoadjuvant dose-dense gemcitabine plus docetaxel and vinorelbine plus epirubicin for operable breast cancer: Improved prognosis in triple-negative tumors. Drugs R D 11: 147-157, 2011

17. Bear HD, Anderson S, Smith RE, Geyer CE Jr, Mamounas EP, Fisher B, Brown AM, Robidoux A, Margolese R, Kahlenberg MS, et al: Sequential preoperative or postoperative docetaxel added to preoperative doxorubicin plus cyclophosphamide for operable breast cancer: National Surgical Adjuvant Breast and Bowel Project Protocol B-27. J Clin Oncol 24: 2019-2027, 2006.

18. Wolmark N, Wang J, Mamounas E, Bryant J and Fisher B: Preoperative chemotherapy in patients with operable breast cancer: nine-year results from National Surgical Adjuvant Breast and Bowel Project B-18. J Natl Cancer Inst Monogr 96-102, 2001.

19. Chollet P, Amat S, Cure H, de Latour M, Le Bouedec G, Mouret-Reynier MA, Ferriere JP, Achard JL, Dauplat J and Penault-Llorca F: Prognostic significance of a complete pathological response after induction chemotherapy in operable breast cancer. Br J Cancer 86: 1041-1046, 2002.

20. Montagna E, Bagnardi V, Rotmensz N, Viale G, Pruneri G, Veronesi P, Cancello G, Balduzzi A, Dellapasqua S, Cardillo A, et al: Pathological complete response after preoperative systemic therapy and outcome: Relevance of clinical and biologic baseline features. Breast Cancer Res Treat 124: 689-699, 2010.
21. von Minckwitz G, Kümmel S, Vogel P, Hanusch C, Eidtmann H, Hilfrich J, Gerber B, Huober J, Costa SD, Jackisch C, et al; German Breast Group: Neoadjuvant vinorelbine-capecitabine versus docetaxel-doxorubicin-cyclophosphamide in early nonresponsive breast cancer: Phase III randomized GeparTrio trial. J Natl Cancer Inst 100: 542-551, 2008.

22. Kurebayashi J, Kanomata N, Yamashita T, Shimo T, Mizutoh A, Moriya T and Sonoo H: Prognostic value of phosphorylated HER2 in HER2-positive breast cancer patients treated with adjuvant trastuzumab. Breast Cancer: Jun 8, 2013 (Epub ahead of print).

23. Yoo C, Ahn JH, Jung KH, Kim SB, Kim HH, Shin HJ, Ahn SH, Son BH and Gong G: Impact of immunohistochemistry-based molecular subtype on chemosensitivity and survival in patients with breast cancer following neoadjuvant chemotherapy. J Breast Cancer 15: 203-210, 2012.

24. Houssami N, Macaskill P, von Minckwitz G, Marinovich ML and Mamounas E: Meta-analysis of the association of breast cancer subtype and pathologic complete response to neoadjuvant chemotherapy. Eur J Cancer 48: 3342-3354, 2012.

25. Suen D, Chow L and Kwong A: Breast-conserving surgery in Hong Kong Chinese women. World J Surg 32: 2549-2553, 2008.

26. Clavarezza M, Turazza M, Aitini E, Saracchini S, Garrone O, Durando A, De Placido S, Bisagni G, Levaggi A, Bighin C, et al: Phase II open-label study of bevacizumab combined with neoadjuvant anthracycline and taxane therapy for locally advanced breast cancer. Breast 22: 470-475, 2013 